\title{
Prognostic Role of Pulse Pressure in the Acute Phase of Myocardial Infarction
}

\author{
Justin Koffi, 1,2*, Christoph Konin1, Yves N'goran', Arnaud Ekou1, Ambroise Gnaba1, \\ Esaie Soya1, Marie Paul N’Cho Mottoh1, Bénédict Boka1, Michel Adoh Adoh'1 \\ ${ }^{1}$ Institute of Cardiology of Abidjan, University of Cocody, Abidjan, Ivory Coast \\ ${ }^{2}$ Hospital of the National Police, Abidjan, Ivory Coast \\ Email: ${ }^{*}$ koffidjinguin@yahoo.fr
}

Received 2 July 2015; accepted 25 August 2015; published 28 August 2015

Copyright (C) 2015 by authors and Scientific Research Publishing Inc.

This work is licensed under the Creative Commons Attribution International License (CC BY). http://creativecommons.org/licenses/by/4.0/

cC) (i) Open Access

\section{Abstract}

Objective: Pulse pressure is a cardiovascular risk factor. The aim of our study was to assess the short and medium term prognosis of myocardial infarction in the African black having a high pulse pressure. Methods: We performed a comparative retrospective study of 200 patients hospitalized in the Cardiology Institute of Abidjan. The first group (100 patients) had a high pulse pressure $(\geq 60 \mathrm{mmHg})$. The second (100 patients) had normal pulse pressure $(\leq 60 \mathrm{mmHg})$. The primary outcome was mortality. Secondary endpoints were represented by hemodynamic complications, rhythmic and conduction disturbances. Both groups of patients were matched. The matching is performed by socio-demographic criteria, the seat of necrosis and cardiovascular risk factors. The authors explained the choice of $60 \mathrm{mmHg}$ as references because in all their studies they have realized that it is from $60 \mathrm{mmHg}$ pulse pressure morbid events that occur in prospective studies and retrospective studies in stiffness of the great arteries is responsible for all these events. Pulse pressure is in itself, an independent cardiovascular risk factor in systolic blood pressure, diastolic blood pressure when associated with myocardial infarction, it becomes from $60 \mathrm{mmHg}$ poor prognostic factor especially in the acute phase. Results: The mean age was $54.46 \pm 10.10$ years for patients with normal pulse pressure and $52.32 \pm 10.89$ years in patients with high pulse pressure. Patients with elevated pulse pressure were twice as left ventricular failure $\left(\mathrm{Chi}^{2}=3.71 ; \mathbf{P}=0.048\right.$ $=2 \mathrm{OR} 95 \% \mathrm{CI}=0.93$ to 4.29 ). These patients had an ejection fraction and fractional shortening double bass $\left(\mathrm{Chi}^{2}=31.23 \mathrm{P}=0.00001, \mathrm{OR}=2.295 \% \mathrm{CI} 0.8\right.$ to 17.4) $10 \mathrm{mmHg}$ for increased pulse pressure we observed an average growth of $18 \%$ mortality rate. Mortality was three times higher in patients with elevated pulse pressure $\left(\mathrm{Khi}^{2}=15,06 \mathrm{ddl}=1 \mathrm{P}=0.0001 \mathrm{OR}=3.3495 \% \mathrm{CI} 1.72\right.$ to 6.52). Conclusion: The high pulse pressure represented an independent poor prognostic factor in the acute phase of myocardial infarction in the black African.

\footnotetext{
${ }^{*}$ Corresponding author.
} 


\section{Keywords}

\section{Myocardial Infarction Pulsed, Pressure, African}

\section{Introduction}

Pulse pressure also known as Differential Blood Pressure is currently considered as a risk factor independent of Systolic Blood Pressure, Diastolic Blood Pressure and Mean Arterial Pressure. It represents a factor independent of cardiovascular risk. The role of this factor is now well quantified in treated and apparently controlled hypertensive subjects and normotensive subjects [1]-[5].

High pulse pressure is both a cardiovascular risk factor and a factor of bad prognostic in the acute phase of myocardial infarction. This risk factor is well studied in Western Countries whereas in Africa in general and in Côte d'Ivoire in particular, few studies have been conducted to assess the prognostic role of pulse pressure in the acute phase of myocardial infarction.

It is in this context and in view of filling this apparent gap that we conducted this comparative study in order to assess pulse pressure as an independent risk factor of excess mortality rate and occurrence of complications in the acute phase of myocardial infarction in Black African subject.

\section{Methodology}

We conducted a retrospective comparative study related to two groups of patients admitted to the Institute of Cardiology of Abidjan for Acute Myocardial Infarction whose pain had been evolving since less than 24 hours from 2003 to 2007. The first group consisted of 100 patients who presented upon admission high pulse pressure simultaneously with myocardial infarction. The second group consisted of 100 patients hospitalized during the same period for myocardial infarction with normal pulse pressure. It was a case-control study (one case for each control subject) where cases were patients with high pulse pressure and control subjects patients with normal pulse pressure.

The matching of the two populations was conducted according to the age, gender, the site of necrosis and major cardiovascular risk factors (High Blood Pressure, tobacco, diabetes, obesity, hypercholesterolemia, hypertriglyceridemia). Endpoints in each group of population were potential hemodynamic, rhythmic, conductive complications as well as mortality in the acute phase of myocardial infarction.

The diagnosis of myocardial infarction was based on clinical criteria (acute coronary syndrome resistant to nitroglycerin) electrocardiographic (Pardee waves, Q wave), biological (cardiac enzymes elevation, troponin I elevation).

Pulse pressure was assessed upon admission to the emergency room and during hospitalization.

Furthermore, we calculated the average of different pulse pressures in each patient upon admission and during hospitalization.

Pulse pressure was calculated regardless of the reading method as the difference between Systolic Blood Pressure (SBP) and Diastolic Blood Pressure (DBP) PP $=$ SBP $(140 \mathrm{mmHg})-$ DBP $(80 \mathrm{mmHg})=60 \mathrm{mmHg}$.

Pulse pressure was considered to be high when it exceeded $60 \mathrm{mmHg}$ [6] [7].

All the patients of both groups were treated with sodium heparin using syringe pump, converting enzyme inhibitor, beta blocker, nitrates, antiplatelet drugs and statin. None of the patients received thrombolytic or angioplasty revascularization treatment .A this time in our cardiology center was practiced these treatments

Statistical analysis of data was carried out by means of the software Epi Info 6 version 6.04. The comparison of both populations was conducted thanks to the odds ratio calculation, confirmed by the Chi ${ }^{2}$ test with a threshold of $5 \%$. Numbers less than 5 were compared by means of the Fischer Test with a threshold of $5 \%$. The survival curve was drawn according to the Kaplan-Meir procedure.

The limitations of our study: a retrospective study, there was bias, since some records were incomplete, the management was not optimal due to the lack of thrombolysis, the absence of coronary angiography.

\section{Results}

The mean age was 52.3 years for patients with high pulse pressure and 54.4 years for subjects with normal pulse 
pressure. We observed a male predominance in both populations (68.5\% vs 31.5\%, $\mathrm{P}=0.55)$. The average of pulse pressure was $60 \mathrm{mmHg}$ in patients with high pulse pressure and $45 \mathrm{mmHg}$ in those with normal pulse pressure.

\section{Comparative Study}

The frequency of patients who presented a complicated evolution during their hospitalization was significantly higher in the group of patients with high pulse pressure compared to those with normal pulse pressure.

As a matter of fact, patients with high pulse pressure were two times more at risk of developing left ventricular failure compared to those with normal pulse pressure $\left(\mathrm{Chi}^{2}=3.71\right.$, ddl $=1, \mathrm{P}=0.048, \mathrm{OR}=1.99, \mathrm{CI}$ of $95 \%=$ 0.93 - 4.29).

The comparative study of rhythm disorders in both populations did not reveal a correlation between pulse pressure elevation in the acute phase of myocardial infarction and the occurrence of rhythm disorders. $\left(\mathrm{Chi}^{2}=0\right.$, $\mathrm{ddl}=1, \mathrm{P}=0.72$, OR $=1$, CI of $95 \%=0.54-2.35)$, the same applied to conduction disorders $\left(\mathrm{Chi}^{2}=2.26\right.$, $\mathrm{ddl}=$ $1, \mathrm{P}=0.133$, OR $=0.532$, CI of $95 \%=0.172-1.648)$.

The echography of left ventricular ejection fraction revealed a statistically significant difference between patients with high pulse pressure and those with normal pulse pressure. Patients with high pulse pressure were three times more at risk of developing a Low Ejection Fraction $(\mathrm{EF}<0.55)$ than those with normal pulse pressure. The same applied to shortening fraction. $\left(\mathrm{Chi}^{2}=23.63\right.$, $\mathrm{ddl}=1, \mathrm{P}=0.0000012$, CI of 95\% $\left.=0.28-7\right)$.

The collapse of the ejection fraction and shortening fraction in the acute phase of myocardial infarction was correlated with the increase in pulse pressure.

There were moreover a significant difference between patients with high pulse pressure and those with normal pulse pressure regarding complicated evolution. Pulse pressure elevation constituted a risk factor of occurrence of derogative events (complications and deaths) in the acute phase of myocardial infarction. $\left(\mathrm{Chi}^{2}=81.40\right.$, ddl $=$ $1, \mathrm{P}=0.0000)$.

For an increase of $10 \mathrm{mmHg}$ in pulse pressure, we observed an average rise of the mortality rate by $18 \%$. Mortality was three times higher in patients with high pulse pressure than in patients with normal pulse pressure. $(\mathrm{OR}=3.3$, CI of $95 \%=1.72-6.52)$.

After a two-month follow-up, survival experienced a decrease, sign of a rise in mortality between admission and the first week in both populations but particularly noticeable in patients with high pulse pressure. This decrease worsened after the third week of hospitalization in patients with high pulse pressure.

Excess death rate factors in hospitals are summarized in the table. They were mainly represented by a pulse pressure elevation beyond $60 \mathrm{mmHg}$, left ventricular failure; low ejection fraction was 50\% [Table 1].

All the other factors such as: High Blood Pressure, Tobacco, Diabetes, Dyslipidemia, Stress Obesity, MI Territory were matched [Table 2].

Survival experienced a decrease, sign of a rise in mortality between admission and the first week in both populations but particularly noticeable in patients with high pulse pressure [Figure 1].

This accentuated decrease worsened after the third week of hospitalization in patients with high pulse pressure.

Table 1. Characteristic of the initial study populations.

\begin{tabular}{cccccc}
\hline Variables & $\begin{array}{c}\text { High PP } \\
(\mathrm{N}=100)\end{array}$ & $\begin{array}{c}\text { Normal PP } \\
(\mathrm{N}=100)\end{array}$ & OR & IC95\% & Chi $^{2}$ \\
\hline Age & 52.3 & 54.4 & & 6.04 & 0.61 \\
Sex M/F & $62 / 38$ & $75 / 25$ & 0.544 & 3.91 & 0.068 \\
\hline
\end{tabular}

Table 2. Survival summary of both populations.

\begin{tabular}{rrrrrrrrrrrrrrrrrrr}
\hline & J0 & J2 & J4 & J6 & J8 & J10 & J12 & J14 & J16 & J18 & J20 & J22 & J24 \\
\hline Normal PP & 99 & 94 & 92 & 92 & 88 & 87 & 87 & 87 & 86 & 85 & 85 & 85 \\
High PP & 97 & 83 & 75 & 73 & 66 & 62 & 60 & 58 & 56 & 56 & 53 & 49 & 46 \\
\hline
\end{tabular}




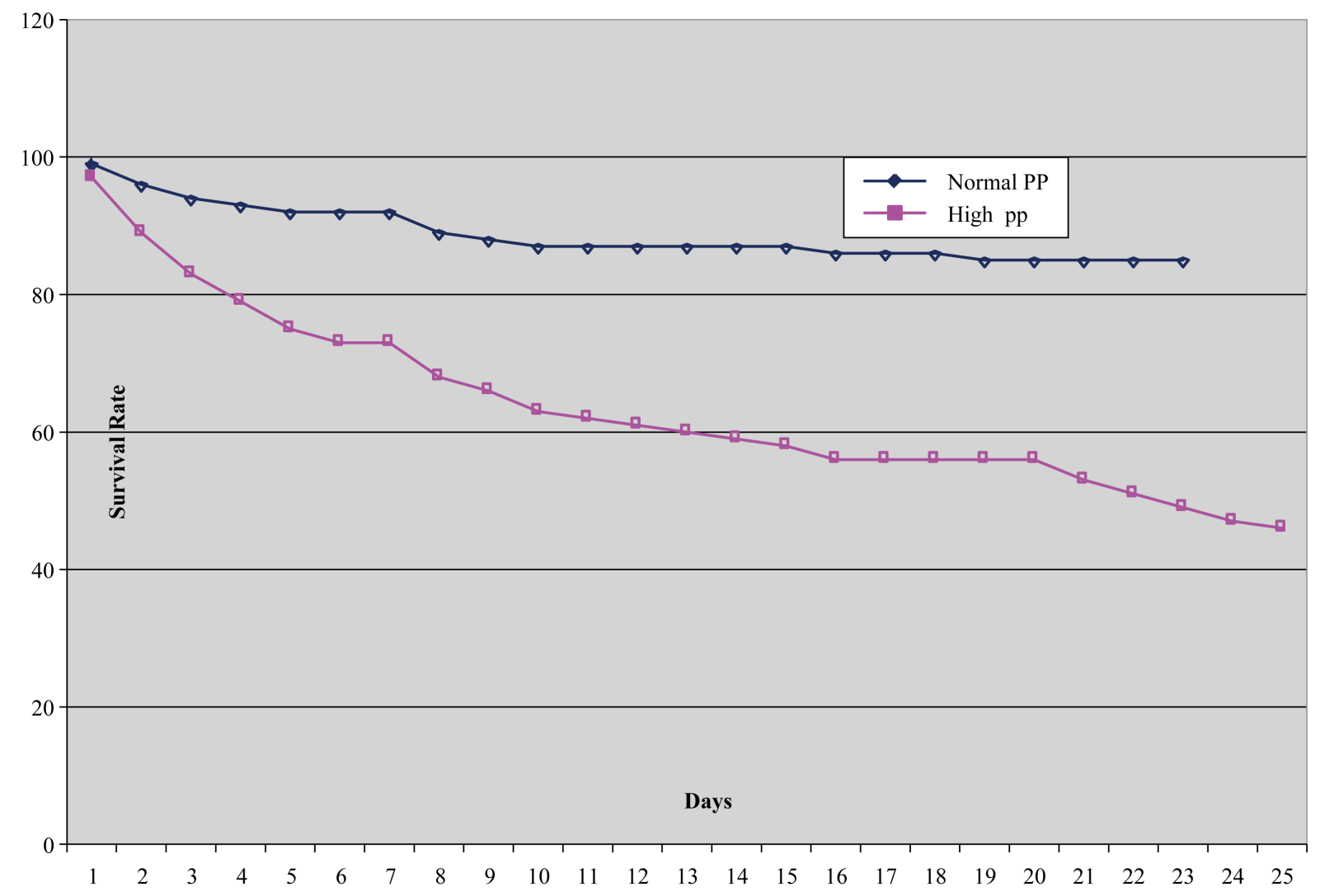

Figure 1. Survival curve.

\section{Discussion}

Epidemiologycally, the mean age of the first population with high pulse pressure was 52.3 years. There were mainly male subjects (70\%). The mean age of the second population of patients was 54.4 years. $67 \%$ of them were male. Fewer studies have been carried out on pulse pressure in Black Africa in order to allow for a comparative approach of our results. Studies conducted in France revealed that the mean age of patients with high pulse pressure was 55 years [8] [9]. Moreover, these studies showed that pulse pressure was a major risk factor that needed to be considered in the acute phase of myocardial infarction.

Pulse Pressure depends on three hemodynamic factors: left ventricular ejection rate, aortic parietal stiffness degree and pressure waves. Ventricular ejection causes a disturbance of the aortic wall triggering a propagation of the pressure wave along the arterial tree. As the wave moves in territories with more and more reduced diameter and increasingly rigid wall, it follows a deformation of the pressure curve along the arterial tree [10]. This mechanism could account for the occurrence of complications with as a result the rise of mortality in the acute phase of myocardial infarction. Patients with high pulse pressure were two times more at risk of developing an unfavorable evolution than those with normal pulse pressure ( $\mathrm{OR}=2)$. High pulse pressure appears as a bad prognostic factor in the acute phase of myocardial infarction.

The prognostic role of Pulse Pressure on cardiovascular affections is well defined. In our study, patients with high pulse pressure were two times more prone to left ventricular failure in the acute phase of myocardial infarction than those with normal pulse pressure. As well, an increase of $10 \mathrm{mmHg}$ in the pulse pressure was correlated to an increase of $26.6 \%$ of complications. Our results were in line with the results of Chae et al. [11] who revealed that an increase of $10 \mathrm{mmHg}$ in the pulse pressure goes along with an increase of left ventricular failure in the acute phase of myocardial infarction by $14 \%$. Vaccarino et al. showed in a recent study that an increase in the pulse pressure by $10 \mathrm{mmHg}$ was associated with an increase of heart failure risk by $32 \%$ [12]. High pulse pressure is moreover a determining factor in the occurrence of hemodynamic complications in the acute phase of myocardial infarction in Black African subjects [13] [14]. 
In myocardial infarction, rhythm disorders are part of early complications. Are those atrial or ventricular heart rates related in one way or the other to the rise of the pulse pressure in the acute phase of myocardial infarction? This theme is nearly not dealt with in the literature and results do not underline significant difference between subjects with high pulse pressure and subjects with normal pulse pressure regarding rhythm disorders. Is it however possible to assert that no link exist between the level of pulse pressure and the occurrence of heart rhythm disorders? More objective answers could be obtained in future works with more systematic stress on cardiac rhythm disorders in the acute phase of myocardial infarction.

With regards to conduction disorders we did not observe statistically significant difference between cases and control subjects. I.e. patients with high pulse pressure are not more at risk of developing conduction disorders than those with normal pulse pressure in the acute phase of myocardial infarction.

Fewer data exist in Africa relating to the impact of pulse pressure on mortality in the acute phase of myocardial infarction unlike in the Western world, where many studies have been conducted. From our stand we stressed that an increase by $10 \mathrm{mmHg}$ of pulse pressure had as consequence an average increase of the mortality rate by $18 \%$ [15]-[17].

Pernenkil et al. showed that a rise in the pulse pressure during myocardial infarction correlated with an annual mortality of 9\% [18] [19]. Domanski et al. assessed the role of pulse pressure in terms of cardiovascular risk factor in a population concluded that pulse pressure was an independent predictor of cardiovascular mortality, coronary diseases and total mortality [20]. Thus according to the same authors an increase of pulse pressure by $10 \mathrm{mmHg}$ was associated with an increase of cardiovascular death rate by $26 \%$. Madhavan and coll. underlined that pulse pressure only and not diastolic blood pressure and systolic blood pressure, was a predictive of myocardial infarction [21]. As a matter of fact the relative risk of coronary events in patients with their pulse pressure exceeding $63 \mathrm{mmHg}$ was higher compared to hypertensive patients with a pulse pressure under $47 \mathrm{mmHg}$.

The implication of pulse pressure in cardiovascular morbidity and mortality was also proved in a population of patients who presented myocardial infarction followed by a heart failure. A recent analysis of the results of the study of Danchin [6] showed that the risk of complication and cardiovascular mortality was positively correlated to the amplitude of pulse pressure recorded in the acute phase and after myocardial infarction. Benetos and coll. revealed that cardiovascular mortality was positively correlated to the level of pulse pressure, after adjustment to the age, to the level of mean pressure and to other risk factors [7] [22]. According to the same study, pulse pressure was a significant determining factor of coronary mortality. In a former analysis, it was observed that a pulse pressure exceeding $65 \mathrm{mmHg}$ could be accompanied by a frank elevation of coronary cardiovascular risk, even if absolute values of systolic blood pressure and diastolic blood pressure did not exceed the higher normal limit [20]. For example, a patient with a blood pressure reading of 138/68 $\mathrm{mmHg}$ (pulse pressure $=70$ mmHg) with a coronary risk higher than 50\% compared to a patient with a blood pressure reading of $125 / 78$ mmHg (pulse pressure reading of $47 \mathrm{mmHg}$ ). We obtained results in line with this mortality rate for a pulse pressure higher than $60 \mathrm{mmHg}$.

Patients with high pulse pressure died two times more than those with normal pulse pressure in the immediate phase of myocardial infarction. Regarding myocardial constants some authors of whom Konin et al. revealed that one of the mortality causes of myocardial infarction in the acute phase is the collapse of ejection fraction and shortening fraction [23] [24]. Bouraoui revealed also that one of the immediate death causes in the acute phase of myocardial infarction is left ventricular dysfunction [25]. In our study, patients with high pulse pressure developed two times low ejection fraction and shortening fraction than those with normal pulse pressure.

\section{Conclusion}

This hospital-based case-control study aiming at assessing the prognostic role of pulse pressure in the acute phase of myocardial infarction enabled us to underline the following facts: Pulse pressure elevation is a factor of bad prognostic because it increases significantly hemodynamic complications, the incidence of left ventricular dysfunction and mortality in the acute phase of myocardial infarction.

\section{References}

[1] Guideline Subcommittee (1999) Word Heath Organization-International Society of Hypertension Guideline for the Management of Hypertension. Journal of Hypertension, 17, 151-183.

[2] Joint National Committee on Detection (1997) Evaluation and Treatment of High Blood Pressure. The Sixth Report of 
the Joint National Committee on Prevention and Treatment of High Blood Pressure (JNC VI). Archives of Internal Medicine, 157, 2413-2446. http://dx.doi.org/10.1001/archinte.1997.00440420033005

[3] Safar, M.E. and London, G.M. (1994) The Arterial System in Human Hypertension. In: Swales, J.D., Ed., Textbook of Hypertension, Blackwell Sc, London, 85-102.

[4] Nichols, W.W. and O’Rourke, M. (1998) McDonald’s Blood Flow in Arteries. Theoretical, Experimental and Clinical Principle. 4th Edition, Arnold E., London, 54-113, 201-222, 284-292, 347-401.

[5] Darne, B., Girerd, X., Safar, M., Cambien, F. and Guize, L. (1989) Pulsatile versus Steady Component of Blood Pressure: A Cross-Sectional Analysis and a Prospective Analysis on Cardiovascular Mortality. Hypertension, 13, 392-400. http://dx.doi.org/10.1161/01.HYP.13.4.392

[6] Danchin, N. (2002) Pulse Pressure and Coronary Disease. Archives of Disease and Vascular, 95, 7-10.

[7] Benetos, A., Rudnich, A., Safar, M. and Guize, L. (1998) Pulse Pressure and Cardiovascular Mortality in Normotensive and Hypertensive Subjects. Hypertension, 32, 560-564. http://dx.doi.org/10.1161/01.HYP.32.3.560

[8] Mitchell, G.F., Moye, L.M., Braunwald, E., Rouleau, J.L., Bernstein, V., Geltman, E.M., Flaker, G.C. and Pfeffer, M.A. (1997) For the Save Investigators. Sphygmomanometrically Determined Pulse Pressure Is a Powerful Independent Predictor of Recurrent Events after Myocardial Infarction in Patients with Impaired Left Ventricular Function. Circulation, 96, 4254-4260. http://dx.doi.org/10.1161/01.CIR.96.12.4254

[9] Black, H.R. (1999) Paradigm Has Shifted, to Systolic Blood Pressure. Hypertension, 34, 386-387. http://dx.doi.org/10.1161/01.HYP.34.3.386

[10] Giovanni, D.S., Mary, J., Michael, H. and Alderman Mauzizo, G.D.D. (2005) Is High Pulse Pressure a Marker of Preclinical Cardiovascular Disease? Hypertension, 45, 575-579. http://dx.doi.org/10.1161/01.HYP.0000158268.95012.08

[11] Grossman, W. (2000) Defining Diastolic Dysfunction. Circulation, 101, 2020-2021. http://dx.doi.org/10.1161/01.CIR.101.17.2020

[12] Schram, M.T., Kostense, P.J., Van Dijk, R.A., Dekker, J.M., Nijpels, G. and Boutier, L.M. (2002) Diabetes, Pulse Pressure and Cardiovascular Mortality: The Hoorn Study. Journal of Hypertension, 20, 1743-1751. http://dx.doi.org/10.1097/00004872-200209000-00017

[13] Black, H.R. and Yi, J.Y. (1996) A New Classification for Hypertension Based on Relative and Absolute Risk with Implications for Treatment and Reimbursement Hypertension. Hypertension, 28, 719-724. http://dx.doi.org/10.1161/01.HYP.28.5.719

[14] Vasan, R.S. and Larson, M.G. (1999) Congestive Heart Failure in Subjects with Normal versus Reduced Left Ventricular Ejection Fraction. Journal of the American College of Cardiology, 3, 1948-1955. http://dx.doi.org/10.1016/S0735-1097(99)00118-7

[15] Sagie, A., Larson, M.G. and Levy, D. (1993) The Natural History of Borderline Isolated Systolic Hypertension. New England Journal of Medicine, 329, 1912-1917. http://dx.doi.org/10.1056/NEJM199312233292602

[16] Warner, J.G., Metzger, C., Kitzman, D.W., Wesley, D.J. and Little, W.C. (1999) Losartan Improves Exercise Tolerance in Patients with Diastolic Dysfunction and a Hypertensive Response to Exercise. Journal of the American College of Cardiology, 33, 1567-1572. http://dx.doi.org/10.1016/S0735-1097(99)00048-0

[17] Madhavan, S., Ooi, W.L., Cohen, H. and Alderman, M.H. (1994) Relation of Pulse Pressure and Blood Pressure Reduction to the Incidence of Myocardial Infarction. Hypertension, 23, 395-401. http://dx.doi.org/10.1161/01.HYP.23.3.395

[18] Chae, C.U., Pfeffer, M.A., Glynn, R.J., Mitchel, G.F., Taylor, J.O. and Hennkens, C.H. (1999) Increased Pulse Pressure and Risk of Heart Failure in the Elderly. JAMA, 281, 634-643. http://dx.doi.org/10.1001/jama.281.7.634

[19] Vaccarino, V., Holford, T.R. and Krumhomlz, H.M. (2000) Pulse Pressure and Risk of Myocardial Infarction and Heart Failure in the Elderly. Journal of the American College of Cardiology, 36, 130-138. http://dx.doi.org/10.1016/S0735-1097(00)00687-2

[20] Pernenkil, R., Vinson, J.M., Shah, A.S., Beckham, V., Wittenbertg, C. and Rich, M.W. (1997) Course and Prognosis in Patients Superior 70 Years of Age with Congestive Heart Failure and Normal versus Abnormal Left Ventricular Ejection Fraction. The American Journal of Cardiology, 79, 216-219. http://dx.doi.org/10.1016/S0002-9149(96)00719-9

[21] Domanski, M.J., Sutton-Tyrrell, K., Mitchell, G.F., Faxon, D.P., Pitt, B. and Sopko, G. (2001) Determinants and Prognostic Information Provided by Pulse Pressure in Patients with Coronary Artery Disease Undergoing Revascularization (The Balloon Angioplasty Revascularization Investigation). The American Journal of Cardiology, 87, 675-679. http://dx.doi.org/10.1016/S0002-9149(00)01482-X

[22] Saeed, M. and Wilson, M.W. (2014) Monitoring the Sequelae of Coronary Microembolization on Myocardium Using Noninvasive Imaging (Review). World Journal of Cardiovascular Diseases, 4, 601-622. http://dx.doi.org/10.4236/wjcd.2014.412073 
[23] Konin, C., Adoh, A.M., Diby, F., Koffi, J. and N'Guetta, R. (2008) Epidemiological and Etiological Profile of Myocardial Infarction Deaths in Abidjan. African Journal of Medicine, 55, 8-9.

[24] Abed, Y. and Jamee, A. (2015) Characteristics and Risk Factors Attributed to Coronary Artery Disease in Women Attended Health Services in Gaza-Palestine Observational Study. World Journal of Cardiovascular Diseases, 5, 9-18. http://dx.doi.org/10.4236/wjcd.2015.51002

[25] Bouraoui, H., Trimche, B. and Ernez-Hajri, S. (2005) Impact of Diabetes on the Prognosis of Myocardial Infarction. Annales de Cardiologie et d'Angéiologie, 54, 55-59. http://dx.doi.org/10.1016/j.ancard.2004.11.009 